\title{
Influence of dietary spices on the fluidity of erythrocytes in hypercholesterolaemic rats
}

\author{
Rayavara K. Kempaiah and Krishnapura Srinivasan* \\ Department of Biochemistry and Nutrition, Central Food Technological Research Institute, Mysore-570020, India \\ (Received 22 May 2004 - Revised 28 September 2004 - Accepted 1 October 2004)
}

\begin{abstract}
In rats rendered hypercholesterolaemic by maintaining them on a cholesterol-enriched diet $(0.5 \%)$ for 8 weeks, as a result of alteration in membrane structural lipids, erythrocytes were observed to be deformed and become more fragile. This deformity and fragility was partially reversed by the two dietary spice principles, curcumin and capsaicin, and the spice, garlic, by virtue of their ability to lower the extent of hypercholesterolaemia. A further insight into the factors that might have reduced the fluidity of erythrocytes in hypercholesterolaemic rats revealed changes in fatty acid profile of the membranes, phospholipid composition of the membrane bilayer, reduced $\mathrm{Ca}^{2+}, \mathrm{Mg}^{2+}$-ATPase, and reduction in the sensitivity of erythrocytes to concanavaline A. Dietary capsaicin appeared to counter these changes partially in hypercholesterolaemic rats. Electron spin resonance (ESR) spectra and fluorescence anisotropy parameters also revealed altered fluidity of erythrocytes in hypercholesterolaemic rats. Dietary capsaicin and curcumin significantly reversed this alteration. Scanning electron microscopic examination revealed that the echinocyte population was increased in the erythrocytes of hypercholesterolaemic rats, and this was significantly countered by dietary capsaicin. The membrane protein profile and the active cation efflux appeared to be unaffected in the hypercholesterolaemic situation.
\end{abstract}

Dietary spices: Hypercholesterolaemia: Fluidity of erythrocytes: Membrane fatty acid profile: Phospholipid asymmetry

Spices, which are consumed as food adjuncts to enhance the sensory quality of foods, impart characteristic flavour, aroma and colour to foods. In the past three decades, many beneficial physiological effects of spices have been experimentally documented, of which the hypolipidaemic potential of a few spices is likely to have far-reaching beneficial implications (Srinivasan, 2000). The importance of blood cholesterol levels and of lipoproteins in relation to atherosclerosis and coronary heart disease is well known. The spices turmeric (Curcuma longa), red pepper (Capsicum annuum), fenugreek (Trigonella foenumgraecum), garlic (Allium sativum) and onion (Allium cepa) have been documented to have significant hypolipidaemic influence in a variety of experimental animal systems and the latter three spices are found to be efficacious in human studies too (Srinivasan et al. 2004).

Hyperlipidaemic conditions such as those encountered either during continued intake of atherogenic diets or the one found in poorly controlled diabetes mellitus is believed to affect the fluidity of red blood cells (RBC; Cazana et al. 1990). Hence, it would be rational to examine whether hypolipidaemic spices in the diet would offer any beneficial protective influence on the integrity of erythrocyte membranes, which are presumably altered in the hyperlipidaemic situation. We have recently reported that in rats rendered hypercholesterolaemic by maintaining them on a cholesterol-enriched diet, as a result of alteration in the membrane cholesterol:phospholipid ratio, the structural integrity of RBC was also affected as indicated by increased osmotic fragility (Kempaiah \& Srinivasan, 2002). Dietary curcumin, capsaicin and garlic appeared to correct this increased fragility of erythrocytes. We have also recently examined the antioxidant status of erythrocytes of hypercholesterolaemic and hypertriglyceridaemic rats (Kempaiah \& Srinivasan, 2004a,b), and observed that the depleted intracellular thiols and glutathione content as well as the lowered activity of glutathione reductase in the hypercholesterolaemic situation were effectively countered by these dietary hypocholesterolaemic spices (Kempaiah \& Srinivasan, 2004a).

In this investigation, we have examined whether a high $(0.5 \%)$ cholesterol diet would have any detrimental influence on the fluidity of erythrocytes. Influence of such a hyperlipidaemic condition on erythrocyte membrane lipids, especially fatty acid profile and phospholipid asymmetry, proteins, membrane-bound enzymes $\mathrm{Na}^{+}, \mathrm{K}^{+}$-ATPase and $\mathrm{Ca}^{2+}, \mathrm{Mg}^{2+}$-ATPase, active transport of cations and fluorescence anisotropy of RBC have been investigated. Further, we have examined the extent to which the two hypocholesterolaemic spice principles, curcumin and capsaicin, and the spice, garlic, in the diet would offer beneficial protective influence on the integrity of erythrocyte membranes, which are presumably altered in the hypercholesterolaemic situation as a result of a modified membrane lipid profile, in view of our earlier evidence that these dietary factors would beneficially prevent the alteration in erythrocyte membrane lipids.

\footnotetext{
Abbreviations: ESR, electron spin resonance; HCD, high-cholesterol diet; PC, phosphatidylcholine; PE, phosphatidylethanolamine; Pi, inorganic phosphate; PS, phosphatidylserine; RBC, red blood cells; SM, sphingomyelin.
} 


\section{Materials and methods}

\section{Materials}

Curcumin, the colouring principle of turmeric (Curcuma longa), and capsaicin, the pungent principle of red pepper (Capsicum annиит), were procured from M/s Fluka Chemie (Buchs, Switzerland). Garlic (Allium sativum) purchased from the local market was freeze dried and powdered. Cholesterol (99\% pure) and bile salts used in animal diets were procured from Sigma Chemical Co. (St Louis, MO, USA). Phospholipase $\mathrm{A}_{2}$ (Naja naja), sphingomyelinase (Staphylococcus aureus), Tris- $\mathrm{HCl}$, ATP, acetylthiocholine iodide, and electrophoretic chemicals were from Sigma Chemical Co. All other chemicals were of analytical grade from SISCO Research Lab (Mumbai, India) or Qualigen Chemicals (Mumbai, India) and the solvents were distilled before use.

\section{Animal treatment}

Animal experiments were carried out taking appropriate measures to minimize pain or discomfort in accordance with the Guidelines laid down by the National Institute of Health (USA) regarding the care and use of animals for experimental procedures and with due clearance from the Institute's Animal Ethics Committee. Female Wistar rats (ten per group) weighing 110-120 g supplied by this Institute's Animal Production Facility were housed in individual stainless steel cages and maintained ad libitum on various experimental diets for 8 weeks. The basal diet consisted of (\%): casein, 21; cane sugar, 10; corn starch, 54; NRC vitamin mixture, 1; Bernhart-Tommarelli modified NRC salt mixture, 4; and refined peanut oil, 10. Hypercholesterolaemia was induced by feeding a cholesterol-enriched diet $(0.5 \%$ cholesterol and $0.125 \%$ bile salts at the expense of an equivalent amount of corn starch in the basal diet). The spice principles or garlic powder were incorporated into the basal diet and high cholesterol diet, replacing an equivalent amount of corn starch to give the various experimental diets containing: curcumin $(0.2 \%)$, capsaicin $(0.015 \%)$ and garlic $(2.0 \%)$. At the end of the feeding period, the rats were fasted overnight and killed the next morning under light diethyl ether anaesthesia. Blood was drawn from the heart into heparinized tubes. Erythrocytes were separated by centrifugation.

\section{Preparation of erythrocyte membranes}

Erythrocyte membranes were prepared according to Dodgi et al. (1963) by suspending $1 \mathrm{ml}$ of packed erythrocytes in $39 \mathrm{ml}$ of 5 mM-phosphate buffer, $\mathrm{pH} 8.2$, in a centrifuge tube. The fluffy membrane pellet collected by centrifugation was washed two or three times with $5 \mathrm{~mm}$-phosphate buffer, $\mathrm{pH} 8 \cdot 2$, and finally suspended in the same phosphate buffer.

\section{Enzyme activities}

$\mathrm{Na}^{+}, \mathrm{K}^{+}$-ATPase activity was assayed according to Vajreswari et al. (1983) in a medium containing $20 \mathrm{~mm}-$ Tris- $\mathrm{HCl}(\mathrm{pH} 7.4)$, $140 \mathrm{~mm}-\mathrm{NaCl}, \quad 14 \mathrm{~mm}-\mathrm{KCl}, \quad 3 \mathrm{~mm}-\mathrm{MgCl}_{2}, \quad 3 \mathrm{~mm}-\mathrm{ATP}$ and $0.2 \mathrm{~mm}$-EDTA in a final volume of $0.5 \mathrm{ml}$ and, additionally, 1 mM-ouabain (in the case of ouabain-sensitive enzyme activity). Inorganic phosphate $(\mathrm{Pi})$ was estimated in the reaction mixture according to Ames (1966) by reacting $0.3 \mathrm{ml}$ of the sample with $0.7 \mathrm{ml}$ of a $1: 6(\mathrm{v} / \mathrm{v})$ mixture of $10 \%$ ascorbic acid and $0.42 \%$ of ammonium molybdate in $0.5 \mathrm{~mm}-\mathrm{H}_{2} \mathrm{SO}_{4}$ at $45^{\circ} \mathrm{C}$ for $20 \mathrm{~min}$, followed by measurement of absorbance at $620 \mathrm{~nm} . \mathrm{Ca}^{2+}, \mathrm{Mg}^{2+}$ ATPase activity of the erythrocyte membranes was determined according to Vajreswari et al. (1983) in a medium containing $80 \mathrm{mM}-\mathrm{NaCl}, 5 \mathrm{~mm}-\mathrm{MgCl}_{2}, 3 \mathrm{~mm}-\mathrm{ATP}, 20 \mathrm{~mm}-$ Tris- $\mathrm{HCl} \quad \mathrm{pH}$ $7.4), 0.5 \mathrm{~mm}-\mathrm{CaCl}_{2}$ and $1 \mathrm{~mm}$-ouabain in a final volume of $0.5 \mathrm{ml}$. Pi was estimated in the reaction mixture as described by Ames (1966). Acetylcholinesterase in erythrocyte membranes was assayed by spectrophotometric measurement of acetylthiocholine using Ellmen's reagent as described by Steck \& Kant (1960).

\section{$S D S-P A G E$}

SDS-PAGE of erythrocyte membrane proteins was carried out on $10 \%$ acrylamide gel according to Fairbanks et al. (1971). After the electrophoresis, the protein bands were visualized by staining with Coomassie Brilliant Blue.

\section{Erythrocyte membrane fatty acids}

Erythrocyte membrane lipid extract was saponified and methylated with $14 \%$ boron trifluoride in methanol to prepare fatty acid methyl esters as described by Morrison \& Smith (1964). Fatty acid methyl esters were analysed on a silica capillary column BP-21 $(30 \mathrm{~mm}, 0.25 \mathrm{~mm}, 0.25 \mu \mathrm{m}$ film) fitted in a Fisons-GC-8000 series with online Chromcard software. The fatty acid methyl esters were separated isothermally at $220^{\circ} \mathrm{C}$ with the injector and detector temperature at 220 and $230^{\circ} \mathrm{C}$, respectively, and nitrogen as carrier gas at $1 \mathrm{ml} / \mathrm{min}$ flow rate. Major peaks of fatty acids were identified by comparing their retention times with those of fatty acid standards.

\section{Phospholipid asymmetry of erythrocyte membranes}

Erythrocytes were treated with phospholipases according to Renooij et al. (1976). Aliquots of $0.25 \mathrm{ml}$ packed cells were incubated at $37^{\circ} \mathrm{C}$ in $5 \mathrm{ml} 0.87 \% \mathrm{NaCl}, 10 \mathrm{mM}-\mathrm{CaCl}_{2}, 0.25 \mathrm{mM}-\mathrm{MgCl}_{2}$ (adjusted to $\mathrm{pH} 7.4$ with Tris) containing $20 \mathrm{IU}$ phospholipase $\mathrm{A}_{2}$ (Naja naja). After $1 \mathrm{~h}, 2 \mathrm{IU}$ sphingomyelinase (Staphylococcus aureus) was added. Parallel incubations were carried out without enzymes. The lysophospholipids that are formed by the action of enzymes are not further degraded and they remain intact in the membrane. One hour after the addition of sphingomyelinase, the cells were spun down and EDTA (final $10 \mathrm{~mm}$ ) was added to terminate the enzyme reaction. The lipids were extracted according to the procedure of Rose \& Oaklander (1965) and phospholipids were separated by TLC on silica gel-H developed with the solvent system chloroform-methanol-acetic acid-water $(50: 25: 8: 4$, by vol.) and Pi was estimated. Phosphorus measurement in the TLC spots was made according to the method of Parker \& Peterson (1965) as modified by Broekhuyse (1968).

\section{Membrane-bound sialic acid and haemoagglutination test}

Sialic acid in erythrocytes was estimated according to Klenk \& Langerbeins (1941) using $N$-acetyl neuraminyl lactate as standard. The haemoagglutination test was done according to Liener (1955) in trypsinized RBC. 


\section{Sodium efflux and potassium influx studies}

Sodium efflux study in erythrocytes was conducted according to Ruiz-Gutierrez et al. (1993). For sodium loading, aliquots of erythrocytes were suspended to a haematocrit of $5 \%$ in $150 \mathrm{~mm}-\mathrm{NaCl}, 2 \cdot 5-\mathrm{mm}$ monosodium phosphate $(\mathrm{pH} 7 \cdot 4$ at $37^{\circ} \mathrm{C}$ ), $1 \mathrm{~mm}-\mathrm{MgCl}_{2}, 10 \mathrm{~mm}$-glucose, $3 \mathrm{~mm}$-inosine and $2 \mathrm{~mm}$-adenine, and were incubated at $37^{\circ} \mathrm{C}$ for $2 \mathrm{~h}$ and then resuspended in the same buffer to a haematocrit of $10 \%$ and incubated at $37^{\circ} \mathrm{C}$ for $10 \mathrm{~min}$. After this loading period, the cells were centrifuged at $1750 \mathrm{~g}$ at $4^{\circ} \mathrm{C}$ for $5 \mathrm{~min}$ and used for sodium efflux study. For sodium efflux measurement, erythrocytes were washed five times in $110 \mathrm{mM}-\mathrm{MgCl}_{2}$ and resuspended to a haematocrit of $25 \%$ in a medium of $75 \mathrm{mM}-\mathrm{MgCl}_{2}, 85 \mathrm{mM}$-sucrose, $10 \mathrm{mM}$-glucose and $10 \mathrm{~mm}$-4-morpholino-propanesulphonic acid-Tris buffer ( $\mathrm{pH} 7 \cdot 4)$. A portion of cells was also used to determine intracellular sodium and potassium employing a digital flame photometer. Sodium-loaded erythrocyte suspension $(0.5 \mathrm{ml})$ was added (final haematocrit of $4-5 \%$ ) to the tubes containing $2 \mathrm{ml}$ of medium containing $75 \mathrm{mM}-\mathrm{MgCl}_{2}, 85 \mathrm{~mm}$-sucrose, $10 \mathrm{mM}$-glucose and $10 \mathrm{~mm}$-4-morpholino-propanesulphonic acid-Tris buffer $(\mathrm{pH} 7 \cdot 4)$ plus $2 \mathrm{mM}-\mathrm{KCl}$ or $1 \mathrm{mM}$-ouabain. The tubes were incubated at $37^{\circ} \mathrm{C}$ for $30 \mathrm{~min}$; chilled at $4^{\circ} \mathrm{C}$ for $5 \mathrm{~min}$ and centrifuged at $1750 \mathrm{~g}$ at $4^{\circ} \mathrm{C}$ for $5 \mathrm{~min}$. External sodium concentrations were measured in the supernatants using a digital flame photometer. $\mathrm{Na}^{+}-\mathrm{K}^{+}$pump activity was taken as the ouabain-sensitive $\mathrm{Na}^{+}$efflux; calculated by subtracting $\mathrm{Na}^{+}$efflux in the medium containing $1 \mathrm{~mm}$-ouabain from that in the medium containing $2 \mathrm{mM}-\mathrm{KCl}$.

Potassium influx study was carried out according to Meenaghan et al. (1985). The erythrocytes were suspended to a haematocrit of $5 \%$ in a medium containing $145 \mathrm{mM}-\mathrm{NaCl}, 10 \mathrm{mM}$-glucose, $25 \mathrm{mM}^{-\mathrm{CaCl}_{2}}, 7.5 \mathrm{mM}-\mathrm{KCl}, 10 \mathrm{mM}-\mathrm{HEPES}(\mathrm{pH} 7.4)$ and incubated for $30 \mathrm{~min}$ at $37^{\circ} \mathrm{C}$ in the presence or absence of $0.2 \mathrm{mM}$ ouabain. After incubation, cells were added to a solution contain-

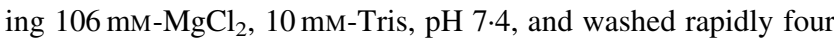
times in this medium by centrifugation at room temperature. The pellet was lysed with $0 \cdot 1 \%$ (w/v) Triton X-100 (500 $\mu \mathrm{l}) ; 5 \%$ (w/ v) TCA $(500 \mu \mathrm{l})$ and the tubes were centrifuged at high speed for 2 min. Potassium was measured in the supernatant using a digital flame photometer. For flame photometric measurement of sodium and potassium, the samples were ashed in an electric muffle furnace at $550^{\circ} \mathrm{C}$ and dissolved in $\mathrm{HCl}$. The solutions were warmed over a boiling water bath; filtered through a membrane filter using deionized water and made up to a known volume.

\section{Fluorescence studies}

Fluorescence studies were made according to the method described by Levin et al. (1990). About $200 \mu \mathrm{g}$ of erythrocyte membrane protein was resealed with $3 \mathrm{ml}$ of $5 \mathrm{~mm}$-PBS containing $1 \mathrm{mM}^{-\mathrm{CaCl}_{2}}, 4 \mathrm{mM}-\mathrm{KCl}$ and $3 \mu \mathrm{l}$ of $6 \mathrm{~mm}-1,6$-diphenyl-1,3,5hexatriene in tetrahydrofuran, was mixed with vigorous agitation and incubated at $37^{\circ} \mathrm{C}$ for $30 \mathrm{~min}$. The fluorescence anisotropy of the label was determined in a Shimadzu RF-5000 spectrofluorophotometer coupled with a polarization unit operating at the excitation wavelength of $356 \mathrm{~nm}$ and the emission wavelength of $428 \mathrm{~nm}$. The anisotropy was calculated according to:

$$
r=\left(I_{\mathrm{VV}}-I_{\mathrm{VH}} \times G\right) /\left(I_{\mathrm{VV}}+I_{\mathrm{VH}} \times G\right)
$$

where $I_{\mathrm{VV}}$ and $I_{\mathrm{VH}}$ are the components of emitted light intensity, parallel and perpendicular, respectively, with reference to the direction of polarization of the excitation light, and $G$ is the correction factor $\left(G=I_{\mathrm{VV}} / I_{\mathrm{VH}}\right)$ used to correct for unequal transmission in the optics. The anisotropy parameter $\left[\left(r_{0} / r\right)-1\right]^{-1}$ was calculated using the limiting anisotropy of 1,6-diphenyl1,3,5-hexatriene $\left(r_{0}=0 \cdot 362\right)$.

\section{ESR spectra of erythrocyte membranes}

ESR spectra of the erythrocyte membranes were made according to Barber et al. (1983). RBC membranes were spin labelled with maleimide-TEMPO in phosphate buffer $(1 \mathrm{mg}$ of label per $25 \mathrm{mg}$ of membrane protein), $\mathrm{pH} 8.0$, at $4^{\circ} \mathrm{C}$ for $16 \mathrm{~h}$ in the dark. The spin-labelled erythrocyte was extensively washed to remove excess unreacted maleimide-TEMPO until no nitroxide EPR signals could be detected in the supernatant. Spin-labelled erythrocyte membranes were transferred to capillary tubes and EPR measurements were made at room temperature in a Bruker EMX X-band ESR spectrometer operating at a frequency of $9 \cdot 5 \mathrm{GHz}$ and a magnetic field of 5000 Gauss.

\section{Scanning electron microscopic study of erythrocytes}

Scanning electron microscopic studies of erythrocytes were done according to Taniguchi et al. (1983). Erythrocytes were fixed by incubating in $1 \%$ glutaraldehyde in $0 \cdot 1 \mathrm{M}$-phosphate buffer, $\mathrm{pH}$ 7.4 , for $3 \mathrm{~h}$ on ice with regular mixing and then thoroughly washed with water and dehydrated by stepwise washing with increasing concentrations of acetone (from 10 to $100 \%$ ). Dehydrated samples were gold coated by sputtering and then examined under the LEO scanning electron microscope (LEO-435VP; LEO Electron Microscopy Co. Ltd., Cambridge, UK.) at different magnifications.

\section{Statistical analysis}

Analytical data are expressed as mean values together with their standard error of the mean, and comparisons between groups were made by subjecting the data to analysis of variance appropriate to completely randomized design with eight animals per group. The mean values were separated by using Duncan's new multiple range test (Dowdy \& Weardew, 1983) and differences were considered significant when $P<0 \cdot 05$.

\section{Results}

\section{Erythrocyte membrane ATPases}

The effect of dietary intake of hypocholesterolaemic spices, curcumin, capsaicin and garlic, on ATPase activities of erythrocytes of hypercholesterolaemic rats induced by a high-cholesterol diet (HCD) is shown in Table 1. Erythrocyte membrane $\mathrm{Na}^{+}, \mathrm{K}^{+}$ATPase activity was unaltered in HCD-fed rats. However, while dietary garlic decreased the ouabain-sensitive $\mathrm{Na}^{+}, \mathrm{K}^{+}$-ATPase activity in hypercholesterolaemic rats, the ouabain-insensitive enzyme activity was generally increased by both the spice principles as well as garlic in hypercholesterolaemic rats. The percentage of ouabain-sensitive components of the total $\mathrm{Na}^{+}, \mathrm{K}^{+}$-ATPase activity in the hypercholesterolaemic rats was not different from that of the basal control group. But, the ouabain-sensitive component of the total $\mathrm{Na}^{+}, \mathrm{K}^{+}$-ATPase activity in the hypercholesterolaemic rats was somewhat lowered in capsaicin or garlic treatment. Activity of $\mathrm{Ca}^{2+}, \mathrm{Mg}^{2+}$-ATPase in erythrocyte membranes was significantly decreased in the 
Table 1. Influence of dietary spices on $\mathrm{Na}^{+}, \mathrm{K}^{+}-\mathrm{ATPase}, \mathrm{Ca}^{2+}, \mathrm{Mg}^{2+}$-ATPase and acetylcholinesterase of erythrocyte membranes in hypercholesterolaemic rats (Mean values with their standard error of the mean of eight animals per group)

\begin{tabular}{|c|c|c|c|c|c|c|c|c|c|c|c|c|}
\hline \multirow[b]{2}{*}{ Animal group/diet } & \multicolumn{2}{|c|}{$\begin{array}{c}\text { Ouabain-insensi- } \\
\text { tive ATPase }\end{array}$} & \multicolumn{2}{|c|}{$\begin{array}{c}\text { Ouabain-sensitive } \\
\text { ATPase }\end{array}$} & \multicolumn{2}{|c|}{ Total ATPase } & \multicolumn{2}{|c|}{$\begin{array}{l}\text { Ouabain-sensi- } \\
\text { tive ATPase as } \\
\% \text { of total }\end{array}$} & \multicolumn{2}{|c|}{$\begin{array}{c}\mathrm{Ca}^{2+}-\mathrm{Mg}^{2+}- \\
\text { ATPase }\end{array}$} & \multicolumn{2}{|c|}{$\begin{array}{l}\text { Acetylcholin- } \\
\text { esterase }\end{array}$} \\
\hline & Mean & SEM & Mean & SEM & Mean & SEM & Mean & SEM & Mean & SEM & Mean & SEM \\
\hline Basal control & 0.180 & $0.005^{\mathrm{a}}$ & 0.154 & $0.005^{a}$ & 0.334 & $0.006^{a}$ & $46 \cdot 1$ & $1 \cdot 30^{\mathrm{a}}$ & 0.221 & $0.007^{a}$ & $149 \cdot 3$ & $7 \cdot 00^{\mathrm{a}}$ \\
\hline Basal curcumin & 0.182 & $0.008^{a}$ & 0.150 & $0.005^{a}$ & 0.332 & $0.007^{\mathrm{a}}$ & $45 \cdot 2$ & $1.51^{a}$ & 0.228 & $0.011^{a}$ & $160 \cdot 9$ & $5.51^{a}$ \\
\hline Basal capsaicin & 0.186 & $0.002^{a}$ & 0.154 & $0.005^{a}$ & 0.340 & $0.007^{\mathrm{a}}$ & $45 \cdot 3$ & $1.51^{a}$ & 0.229 & $0.010^{\mathrm{a}}$ & $148 \cdot 1$ & $2 \cdot 61^{a}$ \\
\hline HCD control & 0.181 & $0.003^{a}$ & 0.164 & $0.004^{\mathrm{a}}$ & 0.345 & $0.006^{\mathrm{a}}$ & $47 \cdot 5$ & $1 \cdot 16^{\mathrm{a}}$ & 0.166 & $0.009^{c}$ & $158 \cdot 4$ & $7 \cdot 54^{a}$ \\
\hline HCD curcumin & 0.198 & $0.003^{b}$ & $0 \cdot 161$ & $0.006^{a}$ & 0.359 & $0.007^{\mathrm{a}}$ & $44 \cdot 8$ & $1 \cdot 13^{a}$ & 0.212 & $0.010^{a}$ & 181.4 & $4 \cdot 64^{b}$ \\
\hline HCD capsaicin & 0.205 & $0.004^{b}$ & 0.149 & $0.008^{a}$ & 0.354 & $0.010^{\mathrm{a}}$ & $42 \cdot 1$ & $2.06^{b}$ & 0.220 & $0.016^{\mathrm{a}}$ & $150 \cdot 8$ & $4 \cdot 19^{a}$ \\
\hline HCD garlic & 0.220 & $0.010^{c}$ & 0.128 & $0.008^{b}$ & 0.348 & $0.008^{\mathrm{a}}$ & $36 \cdot 8$ & $2 \cdot 30^{\mathrm{C}}$ & 0.182 & $0.010^{C}$ & $161 \cdot 0$ & $6 \cdot 39^{a}$ \\
\hline
\end{tabular}

HCD, high-cholesterol diet.

ATPase units: $\mu \mathrm{mol}$ inorganic phosphate liberated $/ \mathrm{h}$ per $\mathrm{mg}$ protein; acetylcholinesterase units: $\mu \mathrm{mol} / \mathrm{min}$ per $\mathrm{mg}$.

$\mathrm{a}, \mathrm{b}, \mathrm{c}$ Values within columns with the same superscript letter were not significantly different $(P>0.05)$.

hypercholesterolaemic situation (25\% decrease over basal control). Curcumin and capsaicin feeding effectively reversed this alteration in the enzyme activity. Garlic also countered the reduced enzyme activity to some extent. Acetylcholinesterase activity in erythrocyte membranes was unchanged by feeding a HCD (Table 1). The two spice principles or garlic in the diet did not influence the enzyme activity either.

Membrane-bound sialic acid in the erythrocytes of hypercholesterolaemic rats was unchanged and also not influenced by dietary capsaicin (Table 2). Erythrocytes of hypercholesterolaemic rats were more sensitive to haemagglutination by concanavaline A. Dietary capsaicin was observed to reduce significantly the sensitivity of erythrocytes to concanavaline A.

\section{Erythrocyte membrane fatty acids}

Fatty acid composition of erythrocyte membrane lipids in hypercholesterolaemic rats and the influence of dietary capsaicin on this are presented in Table 3. The proportion of PUFA $18: 2$, $22: 5$ and $22: 6$ were significantly decreased in the erythrocyte membranes of hypercholesterolaemic rats. MUFA 14:1 and 18:1 were significantly increased in the erythrocyte membranes of hypercholesterolaemic rats. As a consequence, total unsaturated fatty acid concentration was significantly higher (57.2\% of the total) in the HCD control group compared to its value in the basal control group $(51 \%)$. Among the saturated fatty acids, 18:0 concentration was significantly lower in the erythrocyte membranes of the HCD control group and consequently, the total saturated fatty acid concentration was lower $(42.8 \%)$ compared to the basal control animals (49\%). Dietary capsaicin effectively countered the alteration in the erythrocyte membrane's MUFA 14:1 only in the hypercholesterolaemic situation. Dietary capsaicin also partially countered the decrease in the PUFA 18:2 and $22: 5$. Besides, dietary capsaicin increased the concentrations of membrane fatty acids $18: 3$ and $20: 2$ in the hypercholesterolaemic situation. Dietary capsaicin was not effective in restoring the decreased concentration of the saturated fatty acid 18:0 in the erythrocyte membranes of the HCD group. In rats fed the basal diet, dietary capsaicin decreased the fatty acid 16:1, while fatty acids $18: 3$ and $20: 2$ were increased. The alterations in the erythrocyte membrane composition of total saturated and total unsaturated fatty acids brought about in the hypercholesterolaemic situation, and hence the ratio of unsaturated fatty acid to saturated fatty acid, also remained essentially unchanged in the capsaicin treatment.

\section{Phospholipid profile of erythrocyte membranes}

The phospholipid profile of erythrocyte membranes in hypercholesterolaemic rats as presented in Table 4 indicated significant depletion of phosphatidylcholine (PC) of erythrocyte membranes in hypercholesterolaemic rats. Sphingomyelin (SM) of erythrocyte membranes was slightly but significantly elevated in hypercholesterolaemic rats. This resulted in a significant increase in the SM:PC ratio of the erythrocyte membranes in hypercholesterolaemic rats. So, also, was phosphatidylethanolamine (PE) significantly elevated in erythrocyte membranes of hypercholesterolaemic rats. Dietary capsaicin effectively countered the depletion in PC of the erythrocyte membranes in the hypercholesterolaemic situation and also effectively countered the elevation in SM and PE concentrations of erythrocyte membranes. As a result, the increased SM:PC ratio of erythrocyte membranes was partially countered by dietary capsaicin in HCD-fed rats. Phosphatidylserine (PS) of the erythrocyte membranes was unaltered in hypercholesterolaemic rats.

Fatty acid compositions of individual phospholipids of erythrocyte membranes, namely PC, PE and SM, are given in Figs. 1, 2 and 3, respectively. Among the saturated fatty acids, the relative percentage of 18:0 was significantly lower in all these three phospholipid fractions in the erythrocyte membranes of

Table 2. Influence of dietary capsaicin on membrane-bound sialic acid and haemagglutination of erythrocytes in hypercholesterolaemic rats (Mean values with their standard error of the mean of eight animals per group)

\begin{tabular}{|c|c|c|c|c|}
\hline \multirow[b]{2}{*}{ Animal group/diet } & \multicolumn{2}{|c|}{$\begin{array}{l}\text { Sialic acid }(\mathrm{mg} / \mathrm{ml} \\
\text { packed } \mathrm{RBC})\end{array}$} & \multicolumn{2}{|c|}{$\begin{array}{l}\text { Haemagglutination } \\
(\mu \mathrm{g} \text { Con } \mathrm{A})\end{array}$} \\
\hline & Mean & SEM & Mean & SEM \\
\hline Basal control & 1.014 & $0.026^{a}$ & 0.937 & $0.083^{\mathrm{a}}$ \\
\hline Basal capsaicin & 0.959 & $0.083^{\mathrm{a}}$ & 1.000 & $0.058^{\mathrm{a}}$ \\
\hline HCD control & 1.003 & $0.025^{\mathrm{a}}$ & 0.328 & $0.031^{b}$ \\
\hline HCD capsaicin & 1.051 & $0.026^{\mathrm{a}}$ & 0.656 & $0.061^{c}$ \\
\hline
\end{tabular}

Con A, concanavaline A; HCD, high-cholesterol diet; RBC, red blood cells.

a,b,c Values within columns with the same superscript letter were not significantly different $(P>0.05)$. 
Table 3. Influence of dietary capsaicin on the fatty acid profile of erythrocyte membranes in hypercholesterolaemic rats (Mean values with their standard error of the mean of eight animals per group)

\begin{tabular}{|c|c|c|c|c|c|c|c|c|}
\hline \multirow[b]{2}{*}{ Fatty acid } & \multicolumn{2}{|c|}{ Basal control } & \multicolumn{2}{|c|}{ Basal capsaicin } & \multicolumn{2}{|c|}{ HCD control } & \multicolumn{2}{|c|}{ HCD capsaicin } \\
\hline & Mean & SEM & Mean & SEM & Mean & SEM & Mean & SEM \\
\hline $14: 0$ & 1.029 & 0.005 & 0.985 & 0.051 & 1.089 & 0.081 & 0.987 & 0.077 \\
\hline $16: 0$ & $29 \cdot 12$ & $1 \cdot 158$ & $27 \cdot 71$ & 1.003 & 28.91 & 2.024 & $27 \cdot 84$ & 0.277 \\
\hline $18: 0$ & $18 \cdot 82$ & 0.645 & $20 \cdot 37$ & 0.884 & $12 \cdot 83$ & $0.663^{a}$ & $13 \cdot 10$ & $0.238^{a}$ \\
\hline Saturated & 48.97 & $1 \cdot 810$ & $49 \cdot 06$ & 1.940 & $42 \cdot 83$ & $1 \cdot 870^{\mathrm{a}}$ & 41.98 & $0.590^{a}$ \\
\hline $14: 1$ & $2 \cdot 388$ & 0.207 & 2.693 & 0.181 & 3.256 & $0 \cdot 101^{a}$ & $2 \cdot 180$ & 0.215 \\
\hline $16: 1$ & 1.725 & 0.131 & $1 \cdot 131$ & $0.087^{a}$ & 1.949 & 0.151 & $2 \cdot 120$ & 0.162 \\
\hline $18: 1$ & $10 \cdot 38$ & 0.399 & $10 \cdot 15$ & 0.175 & $19 \cdot 61$ & $0.366^{\mathrm{a}}$ & 18.89 & $0.696^{a}$ \\
\hline $18: 2$ & $6 \cdot 754$ & 0.223 & 6.569 & 0.127 & 4.964 & $0.062^{\mathrm{a}}$ & 5.926 & $0.266^{b}$ \\
\hline $18: 3$ & 0.243 & 0.013 & 0.499 & $0.052^{\mathrm{a}}$ & 0.299 & 0.072 & 1.220 & $0.124^{b}$ \\
\hline $20: 2$ & 0.912 & 0.066 & $1 \cdot 110$ & $0.046^{a}$ & 1.075 & 0.029 & 1.466 & $0.040^{\mathrm{b}}$ \\
\hline $20: 4$ & 23.46 & 0.377 & 23.50 & 0.481 & $22 \cdot 82$ & 0.579 & $22 \cdot 88$ & 0.252 \\
\hline $22: 4$ & 1.224 & 0.187 & 1.193 & 0.050 & $1 \cdot 231$ & 0.099 & 1.095 & 0.232 \\
\hline $22: 5$ & 2.475 & 0.077 & 2.528 & 0.069 & 0.951 & $0.060^{\mathrm{a}}$ & 1.376 & $0.174^{b}$ \\
\hline $22: 6$ & 1.729 & 0.135 & 1.605 & 0.071 & 0.973 & $0.037^{a}$ & 0.919 & $0.032^{a}$ \\
\hline Unsaturated & 51.03 & 1.910 & $50 \cdot 94$ & 1.200 & $57 \cdot 17$ & $1 \cdot 520^{\mathrm{a}}$ & 58.02 & $2.590^{a}$ \\
\hline UFA/SFA & 1.042 & 0.039 & 1.038 & 0.024 & 1.335 & $0.035^{a}$ & 1.382 & $0.061^{a}$ \\
\hline Unsaturation index* & $152 \cdot 0$ & 4.69 & 151.9 & 3.58 & 144.6 & 3.84 & 149.9 & $5 \cdot 69$ \\
\hline
\end{tabular}

HCD, high-cholesterol diet; UFA/SFA, ratio of unsaturated fatty acids to saturated fatty acids.

a,b Values within horizontal rows with the same superscript letter were not significantly different $(P>0.05)$.

* The unsaturation index was calculated by multiplying the number of double bonds by the percentage composition of fatty acids and summing the values.

Table 4. Influence of dietary capsaicin on phospholipid profile of erythrocyte membrane in hypercholesterolaemic rats (Mean percentage of total phospholipid values with their standard error of the mean of eight animals per group)

\begin{tabular}{|c|c|c|c|c|c|c|c|c|c|c|c|c|}
\hline \multirow[b]{2}{*}{ Animal group/diet } & \multicolumn{2}{|c|}{ LPC } & \multicolumn{2}{|c|}{ SM } & \multicolumn{2}{|c|}{$\mathrm{PC}$} & \multicolumn{2}{|c|}{ PS } & \multicolumn{2}{|c|}{ PE } & \multicolumn{2}{|c|}{ SM/PC ratio } \\
\hline & Mean & SEM & Mean & SEM & Mean & SEM & Mean & SEM & Mean & SEM & Mean & SEM \\
\hline Basal control & $1 \cdot 17$ & $0.091^{a}$ & $11 \cdot 13$ & $0 \cdot 116^{\mathrm{a}}$ & $45 \cdot 60$ & $0.492^{\mathrm{a}}$ & $15 \cdot 23$ & $0.369^{a}$ & $26 \cdot 87$ & $0.218^{a}$ & 0.244 & $0.003^{a}$ \\
\hline Basal capsaicin & $1 \cdot 20$ & $0.083^{\mathrm{a}}$ & 11.41 & $0.094^{a}$ & $45 \cdot 42$ & $0.354^{a}$ & 15.95 & $0.269^{a}$ & $26 \cdot 02$ & $0.203^{a}$ & 0.251 & $0.002^{a}$ \\
\hline HCD control & $1 \cdot 30$ & $0.058^{\mathrm{a}}$ & 13.61 & $0.207^{\mathrm{b}}$ & 37.05 & $0.286^{b}$ & 14.58 & $0.357^{a}$ & 33.46 & $0.215^{b}$ & 0.367 & $0.003^{b}$ \\
\hline HCD capsaicin & $1 \cdot 15$ & $0.047^{\mathrm{a}}$ & $12 \cdot 07$ & $0.305^{\mathrm{c}}$ & $40 \cdot 04$ & $0.257^{c}$ & 14.98 & $0.167^{\mathrm{a}}$ & 31.77 & $0.209^{c}$ & 0.301 & $0.002^{c}$ \\
\hline
\end{tabular}

${ }^{a, b, c}$ Values within columns with the same superscript letter were not significantly different $(P>0.05)$.

HCD, high-cholesterol diet; LPC, lysophosphatidylcholine; PC, phosphatidylcholine; PE, phosphatidylethanolamine; PS, phosphatidylserine; SM, sphingomyelin.

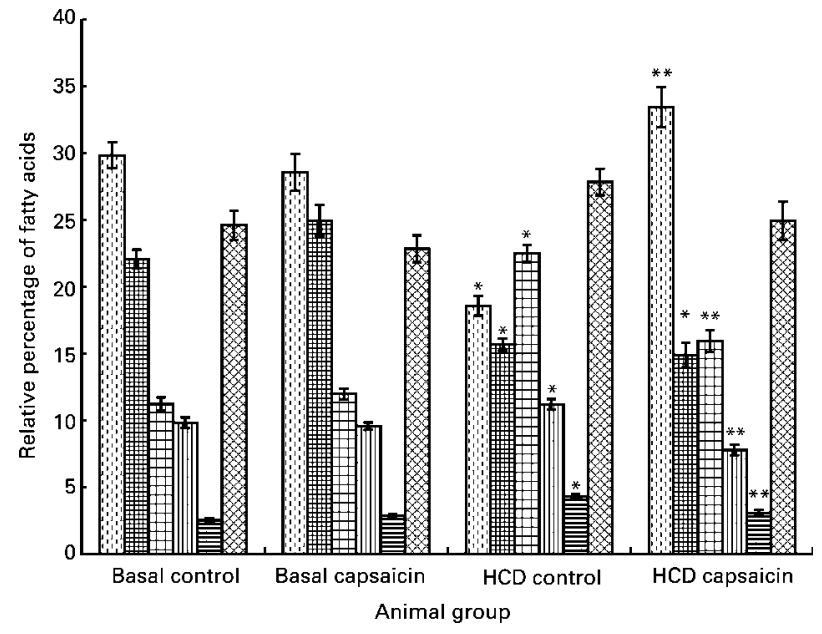

Fig. 1. Fatty acid profile of phosphatidylcholine in erythrocyte membranes of hypercholesterolaemic rats. Values are means with their standard error represented by vertical bars. Mean values were significantly different from that for the corresponding basal control group: ${ }^{*} P<0.05$, ${ }^{\star \star} P<0.01$. HCD, high-

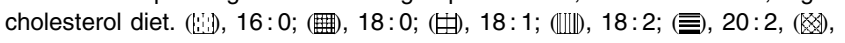
$20: 4$.

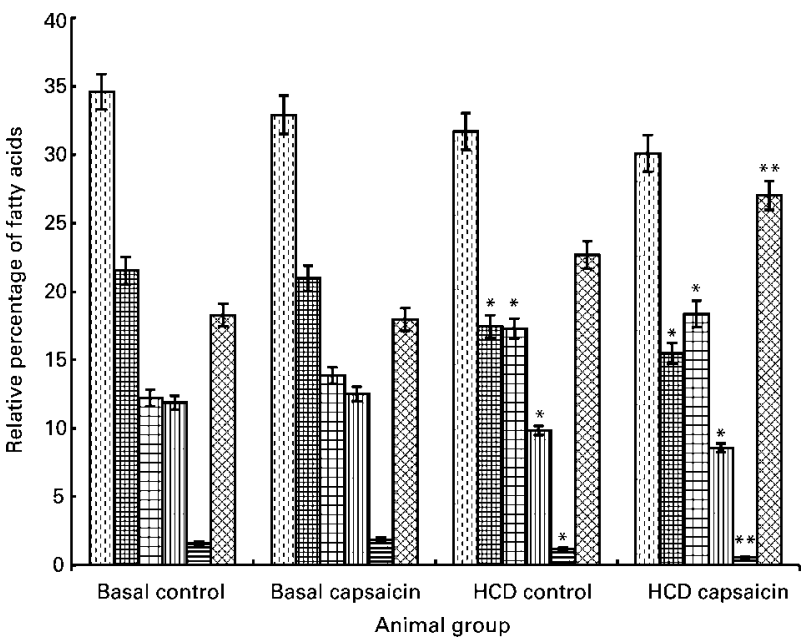

Fig. 2. Fatty acid profile of phosphatidylethanolamine in erythrocyte membranes of hypercholesterolaemic rats. Values are means with their standard errors represented by vertical bars. Mean values were significantly different from that for the corresponding basal control group: ${ }^{\star} P<0.05$. HCD, high-

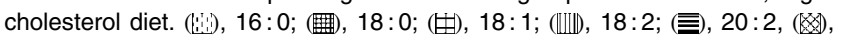
$20: 4$. 


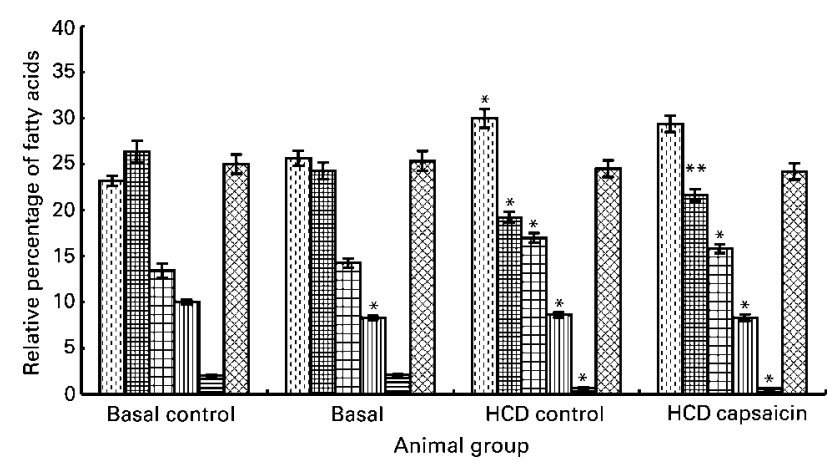

Fig. 3. Fatty acid profile of sphingomyelin in erythrocyte membranes of hypercholesterolaemic rats. Values are means with their standard error represented by vertical bars. Mean values were significantly different from the corresponding basal group: ${ }^{\star} P<0.05,{ }^{*} P<0.01$. HCD, high-cholesterol diet.

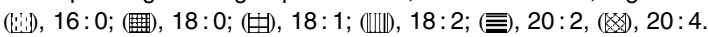

hypercholesterolaemic rats when compared to the respective values in the basal control group. In the case of PC, 16:0 was also lower, while in SM the same was slightly higher in hypercholesterolaemic rats. Thus, the decreases of the saturated fatty acids in the individual phospholipids have contributed to the overall decrease in the proportion of saturated fatty acids (Table 3). Only the lowered value of 16:0 in PC of erythrocytes of hypercholesterolaemic animals was restored by dietary capsaicin. As can be seen in the figures, the observed higher values of $18: 1$ among the fatty acids of erythrocyte membranes of hypercholesterolaemic rats (Table 3) was reflected in the increase of this fatty acid in all the three phospholipid fractions. The increases in fatty acids 18:2 and 20:2 caused in the hypercholesterolaemic situation in the membrane PC is annulled by the decreases brought about in these fatty acids associated with SM. Dietary capsaicin appeared to check the increase in these two unsaturated fatty acids associated with PC of the membrane.

\section{Phospholipid asymmetry of membrane bilayer}

The distribution of various phospholipids in the bilayer of the erythrocyte membrane was determined by the method involving specific degradation of phospholipids by treating the intact erythrocytes with enzymes: phospholipase- $\mathrm{A}_{2}$ (Naja naja) and with both phospholipase- $\mathrm{A}_{2}$ and sphingomyelinase (Staphylococcus aureus). Phospholipase- $\mathrm{A}_{2}$ degrades mostly PC exclusively present in the outer bilayer and to some extent $\mathrm{PE}$, a small portion of which is present in the outer bilayer, into respective lysophospholipids. Treatment of erythrocytes with sphingomyelinase results in the almost total degradation of SM, which is present exclusively in the outer bilayer. Sphingomyelinase also stimulates a further degradation of phosphoglycerides by phospholipase- $\mathrm{A}_{2}$, so that the enzyme combination brings about a further degradation of PC, PE and PS. The non-haemolytic degradation profile of various phospholipids of the erythrocyte membrane by these phospholipases is presented in Table 5.

The asymmetrical phospholipid distribution in the erythrocyte membrane bilayer of hypercholesterolaemic rats as computed by this non-haemolytic phospholipid degradation data is presented in Fig. 4. The total phospholipid of outer and inner membranes of erythrocytes was almost unaltered in the hypercholesterolaemic situation, but the phospholipid asymmetry in the membrane bilayer was altered. Elevated SM under hypercholesterolemia was confined only to the outer membrane as indicated by the study of phospholipid asymmetry in the membrane bilayer. Dietary capsaicin appeared to counter this increase in SM in the outer bilayer of the erythrocyte membrane in hypercholesterolaemic rats. It was found that PC which was decreased under hypercholesterolemia was due to its decrease in both the outer and inner bilayer of the membrane. The phospholipid asymmetry study also indicated that the elevated PE in the erythrocytes of hypercholesterolaemic rats was confined to the inner membrane. Dietary capsaicin partially countered this alteration in the PE asymmetry. PS was significantly higher in the outer membrane of the erythrocytes of hypercholesterolaemic rats and this alteration was partially countered by dietary capsaicin.

\section{Active cation efflux}

The influence of dietary capsaicin on sodium efflux in the erythrocytes of hypercholesterolaemic rats is shown in Table 6. Intracellular $\mathrm{Na}^{+}$concentration was unaltered in the erythrocytes of hypercholesterolaemic rats and capsaicin-fed rats. $\mathrm{Na}^{+}$efflux from $\mathrm{Na}^{+}$-loaded cells was also unaltered in the erythrocytes of the hypercholesterolaemic and the capsaicin-fed rats. The influence of dietary capsaicin on potassium efflux in the erythrocytes of hypercholesterolaemic rats is shown in Table 6. Intracellular $\mathrm{K}^{+}$concentration of erythrocytes was unaltered in the erythrocytes of hypercholesterolaemic rats and capsaicin-fed rats. $\mathrm{K}^{+}$ efflux was also unaltered in the erythrocytes of hypercholesterolaemic and capsaicin-fed rats.

Table 5. Non-haemolytic degradation of membrane phospholipids by phospholipases in erythrocytes of experimental rat groups (Mean percentage degradation values with their standard error of the mean of eight animals per group)

\begin{tabular}{|c|c|c|c|c|c|c|c|c|c|c|}
\hline \multirow[b]{2}{*}{ Animal group/diet } & \multirow[b]{2}{*}{ Degraded by } & \multirow[b]{2}{*}{ SM } & \multicolumn{2}{|c|}{ PC } & \multicolumn{2}{|c|}{ PS } & \multicolumn{2}{|c|}{ PE } & \multicolumn{2}{|c|}{ TP } \\
\hline & & & Mean & SEM & Mean & SEM & Mean & SEM & Mean & SEM \\
\hline & Phospholipase $A_{2}+$ Sphingomyelinase & 100 & 63.07 & 0.517 & 5.98 & 0.225 & 20.53 & 0.184 & $46 \cdot 32$ & 0.38 \\
\hline \multirow[t]{2}{*}{ Basal capsaicin } & Phospholipase $\mathrm{A}_{2}$ & 0 & $48 \cdot 60$ & 0.312 & 0 & & 8.27 & $0 \cdot 256$ & $24 \cdot 22$ & $0 \cdot 16$ \\
\hline & Phospholipase $\mathrm{A}_{2}+$ Sphingomyelinase & 100 & 61.53 & $0 \cdot 319$ & $6 \cdot 12$ & $0 \cdot 127$ & $20 \cdot 80$ & 0.233 & $45 \cdot 75$ & 0.24 \\
\hline \multirow[t]{2}{*}{ HCD control } & Phospholipase $A_{2}$ & 0 & $45 \cdot 69$ & 0.335 & 0 & & $6 \cdot 70$ & 0.195 & $19 \cdot 25$ & $0 \cdot 14$ \\
\hline & Phospholipase $\mathrm{A}_{2}+$ Sphingomyelinase & 100 & $64 \cdot 93$ & 0.546 & $6 \cdot 78$ & $0 \cdot 149$ & $16 \cdot 18$ & 0.226 & $44 \cdot 18$ & 0.37 \\
\hline \multirow[t]{2}{*}{ HCD capsaicin } & Phospholipase $A_{2}$ & 0 & $47 \cdot 42$ & 0.708 & 0 & & $7 \cdot 62$ & 0.258 & 21.43 & 0.32 \\
\hline & Phospholipase $A_{2}+$ Sphingomyelinase & 100 & $64 \cdot 06$ & 0.548 & $6 \cdot 27$ & $0 \cdot 103$ & $19 \cdot 21$ & 0.177 & $44 \cdot 76$ & 0.39 \\
\hline
\end{tabular}

HCD, high-cholesterol diet; PC, phosphatidylcholine; PE, phosphatidylethanolamine; PS, phosphatidylserine; SM, sphingomyelin; TP, total phospholipids. 


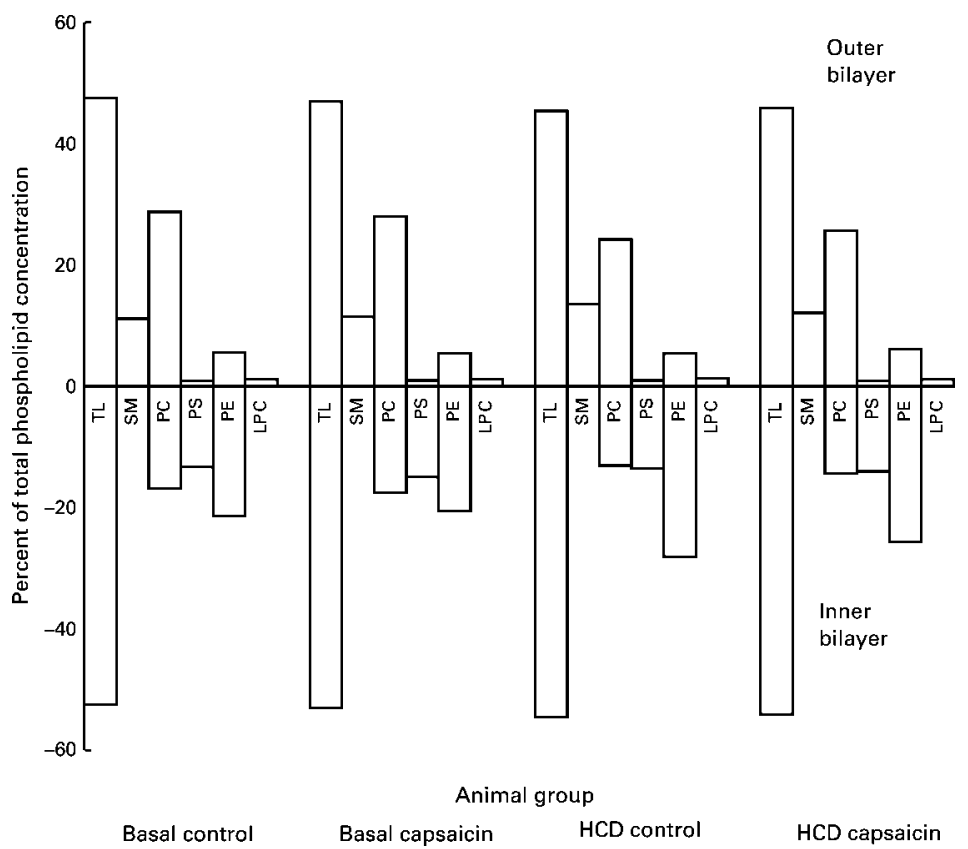

Fig. 4. Probable distribution of phospholipids in inner and outer layers of erythrocyte membranes in different groups of animals. HCD, high-cholesterol diet; LPC, lysophosphatidylcholine; PC, phosphatidylcholine; PE, phosphatidylethanolamine; PS, phosphatidylserine; SM, sphingomyelin; TL, total lipids.

Table 6. Influence of dietary capsaicin on intracellular sodium and potassium concentration and on sodium efflux and potassium influx in erythrocyte of hypercholesterolaemic rats

(Mean values, expressed per litre packed red blood cells, with their standard error of the mean of eight animals per group)

\begin{tabular}{|c|c|c|c|c|c|c|c|c|}
\hline \multirow[b]{2}{*}{ Animal group/diet } & \multicolumn{2}{|c|}{$\begin{array}{l}\text { Intracellular } \mathrm{Na}^{+} \\
(\mathrm{mmol})\end{array}$} & \multicolumn{2}{|c|}{$\begin{array}{l}\text { Ouabain-insensi- } \\
\text { tive } \mathrm{Na}^{+} \text {efflux } \\
\text { from } \mathrm{Na} \text {-loaded } \\
\text { cells }(\mu \mathrm{mol} / \mathrm{h})\end{array}$} & \multicolumn{2}{|c|}{$\begin{array}{l}\text { Intracellular } \mathrm{K}^{+} \\
(\mathrm{mmol})\end{array}$} & \multicolumn{2}{|c|}{$\begin{array}{l}\text { Ouabain-insensi- } \\
\text { tive } \mathrm{K}^{+} \text {influx } \\
(\mu \mathrm{mol} / \mathrm{h})\end{array}$} \\
\hline & Mean & SEM & Mean & SEM & Mean & SEM & Mean & SEM \\
\hline Basal control & 6.08 & $0.552^{\mathrm{a}}$ & $1572 \cdot 1$ & $58 \cdot 7^{a}$ & $60 \cdot 1$ & $2 \cdot 52^{\mathrm{a}}$ & $1037 \cdot 2$ & $35 \cdot 9^{a}$ \\
\hline Basal capsaicin & $5 \cdot 50$ & $0.256^{a}$ & $1724 \cdot 0$ & $83 \cdot 6^{a}$ & $61 \cdot 1$ & $2 \cdot 56^{\mathrm{a}}$ & $1124 \cdot 1$ & $43 \cdot 7^{a}$ \\
\hline HCD control & 5.39 & $0 \cdot 140^{\mathrm{a}}$ & $1414 \cdot 0$ & $52 \cdot 7^{\mathrm{a}}$ & $56 \cdot 4$ & $1 \cdot 40^{\mathrm{a}}$ & 982.4 & $52 \cdot 7^{a}$ \\
\hline HCD capsaicin & $5 \cdot 51$ & $0.123^{a}$ & 1382.2 & $44 \cdot 8^{a}$ & $59 \cdot 1$ & $1 \cdot 23^{\mathrm{a}}$ & $1022 \cdot 3$ & $44 \cdot 8^{a}$ \\
\hline
\end{tabular}

HCD, high-cholesterol diet.

a,b,c Values within columns with the same superscript letter were not significantly different $(P>0.05)$.

Table 7. Influence of dietary curcumin and capsaicin on ESR spectra and fluorescence anisotropy of erythrocyte membranes in hypercholesterolaemic rats

(Mean values with their standard error of the mean of eight animals per group)

\begin{tabular}{|c|c|c|c|c|c|c|}
\hline \multirow[b]{2}{*}{ Animal group/diet } & \multicolumn{2}{|c|}{$\begin{array}{l}\text { ESR spectra (w/s } \\
\text { ratio) }\end{array}$} & \multicolumn{2}{|c|}{ Anisotropy $(r)$} & \multicolumn{2}{|c|}{$\begin{array}{l}\text { Anisotropy } \\
\text { parameter }\end{array}$} \\
\hline & Mean & SEM & Mean & SEM & Mean & SEM \\
\hline Basal control & $10 \cdot 80$ & $0.462^{\mathrm{a}}$ & 0.250 & $0.0027^{a}$ & $2 \cdot 221$ & $0.074^{\mathrm{a}}$ \\
\hline Basal curcumin & 11.02 & $0.812^{\mathrm{a}}$ & 0.247 & $0.0030^{a}$ & $2 \cdot 134$ & $0.083^{\mathrm{a}}$ \\
\hline HCD control & $7 \cdot 80$ & $0.367^{\mathrm{b}}$ & 0.290 & $0.0019^{b}$ & 4.000 & $0.054^{\mathrm{b}}$ \\
\hline HCD curcumin & 11.44 & $0.712^{\mathrm{a}}$ & 0.268 & $0.0011^{a}$ & $2 \cdot 851$ & $0.029^{c}$ \\
\hline Basal control & $9 \cdot 30$ & $0.31^{\mathrm{a}}$ & 0.254 & $0.0050^{\mathrm{a}}$ & 2.346 & $0.0139^{a}$ \\
\hline Basal capsaicin & 8.92 & $0.16^{a}$ & 0.255 & $0.0043^{a}$ & $2 \cdot 367$ & $0.0121^{a}$ \\
\hline HCD control & $6 \cdot 16$ & $0.30^{\mathrm{b}}$ & 0.291 & $0.0021^{b}$ & 4.091 & $0.0060^{b}$ \\
\hline HCD capsaicin & $7 \cdot 96$ & $0.67^{a}$ & 0.271 & $0.0022^{c}$ & 2.982 & $0.0061^{c}$ \\
\hline
\end{tabular}

$\mathrm{HCD}$, high-cholesterol diet.

${ }^{a}, \mathrm{~b}, \mathrm{c}$ Values within columns with the same superscript letter were not significantly different $(P>0.05)$. 


\section{ESR spectra and fluorescence anisotropy}

The ESR spectra of maleimide-TEMPO-labelled erythrocyte membranes of hypercholesterolaemic rats, as influenced by dietary capsaicin and curcumin, are shown in terms of the w/s ratio (ratio of signal amplitude of low field transitions for both the weakly (w) bound and the strongly (s) bound spin labels) calculated from the ESR spectra in Table 7. The w/s ratio in the ESR spectra of maleimide-TEMPO-labelled erythrocyte membranes of hypercholesterolaemic rats was significantly lower compared to that of the basal control $(27.8$ and $33.8 \%$ lower in the two sets of experiments). Feeding capsaicin and curcumin resulted in a significant reversal in this decreased $\mathrm{w} / \mathrm{s}$ value (curcumin produced $100 \%$ reversal, while capsaicin produced $57 \%$ reversal). Data on fluorescence anisotropy and the related anisotropy parameter revealed that the anisotropy parameter was significantly altered in the erythrocyte membranes of hypercholesterolaemic rats, having risen by as much as $74-80 \%$. Dietary capsaicin and curcumin effectively and significantly reversed this alteration, wherein the anisotropy parameter was brought down to a value that was 27 and $28 \%$ higher than the basal control, respectively.

\section{Echinocyte population}

The SDS-PAGE profile of erythrocyte membrane proteins of hypercholesterolaemic rats was unaltered and dietary spices did not influence the protein profile either. Erythrocytes of hypercholesterolaemic rats observed under a scanning electron microscope (Fig. 5) revealed a greater number of echinocytes in hypercholesterolaemic rats ( $16 \%$ of total), while it was $<2.5 \%$ in basal rats.
The number of echinocytes was significantly decreased by dietary capsaicin in hypercholesterolaemic rats (to about $7 \%$ of total).

\section{Discussion}

The fluidity of the erythrocyte membrane is determined by a number of factors including cholesterol content, fatty acid composition of the membrane phospholipids and the protein matrix (Cooper, 1977). In a hypercholesterolaemic situation, where the cholesterol content of blood plasma is increased, the concomitantly higher cholesterol to phospholipids $(\mathrm{C}: \mathrm{P})$ ratio in the blood plasma will have a direct influence on cholesterol transfer from plasma to erythrocytes, resulting in the enrichment of cholesterol in the erythrocyte membrane (Westerman et al. 1970). Increased C:P molar ratio in the erythrocyte membranes of induced hypercholesterolaemic rats $(0.448$ compared to 0.383 in basal control) was in fact shown in our investigation and reported previously (Kempaiah \& Srinivasan, 2002). We have also reported that in erythrocytes from induced hypercholesterolaemic rats, membrane fluidity was slightly diminished as indicated by osmotic fragility, while these cells featured an about $20 \%$ higher than normal C:P ratio (Kempaiah \& Srinivasan, 2002). Inclusion of hypocholesterolaemic spices - curcumin, capsaicin or garlic - in their diet improved the osmotic fragility of erythrocytes, concomitant with the partial restoration of the altered C:P ratio in the erythrocyte membrane (Kempaiah \& Srinivasan, 2002).

When there is an alteration in membrane lipid composition, a change in membrane properties is to be expected. Membrane abnormalities include increased fragility of erythrocytes, or
(A)

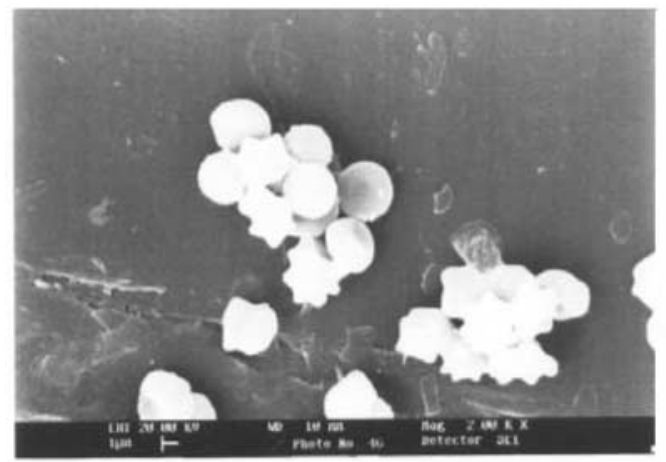

(C)

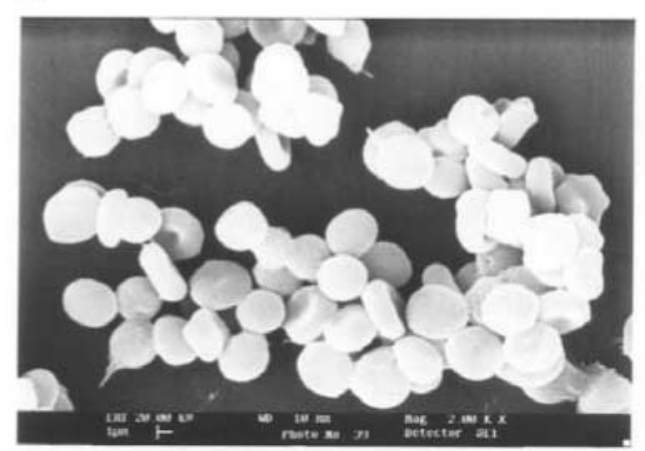

(B)

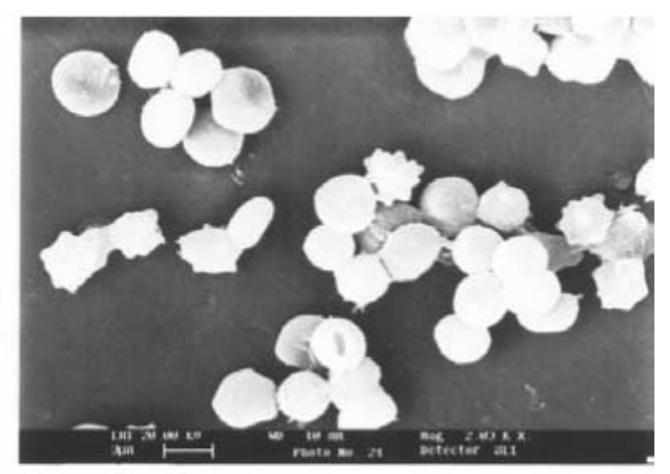

(D)

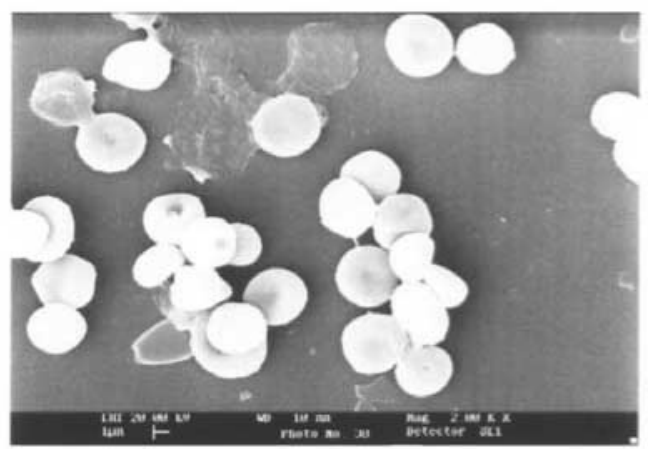

Fig. 5. Scanning electon microscopic images of erythrocytes of hypercholesterolaemic rats as influenced by dietary capsaicin featuring decreased number of echinocytes ( $\times$ 2000). (A), Basal control; (B), basal capsaicin; (C), HCD control; (D), HCD capsaicin. 
else increased resistance to osmotic lysis, reduced activity of acetylcholinesterase, and increased activity content of ouabainsensitive $\mathrm{Na}^{+}, \mathrm{K}^{+}$-ATPase. Osmotic fragility is a determinant of the deformability property of erythrocytes, which is essential for their function and survival against destruction by the spleen. The possibility of increased intracellular calcium accumulation, ATP depletion, and changes in erythrocyte membrane phospholipid and fatty acid composition are examined in the present study to explain the previously observed altered osmotic fragility of erythrocytes in hypercholesterolaemia. The changes in membrane fluidity are further verified in the present investigation by examining other parameters such as ESR measurements, fluorescence anisotropy, active cation transport, etc.

Erythrocytes of hypercholesterolaemic rats in the present study have displayed decreased concentrations of membrane PUFA $18: 2,22: 5$ and $22: 6$, and this was compensated with increased concentrations of MUFA $14: 1$ and $18: 1$, resulting in a net higher concentration of total unsaturated fatty acids. The total saturated fatty acids, with a particular significant decrease in 18:0, was lower compared to normal rats. Most of these alterations in the fatty acid make-up were effectively countered by dietary capsaicin. It has been reported that cholesterol-rich erythrocytes from patients with atherosclerosis develop compensatory changes in phospholipid and fatty acid composition in order to minimize the condensating effect of the excess cholesterol in the erythrocyte membrane (Chien, 1987). The saturated-unsaturated fatty acid ratio is a major determinant of membrane properties. An increased relative concentration of unsaturated fatty acids results in destabilization of the erythrocyte membrane. Thus, changes in fatty acid composition in combination with the $\mathrm{C}: \mathrm{P}$ molar ratio explain the altered susceptibility of erythrocyte membranes of these rats to osmotic lysis. As a result of the increased C:P ratio and of the altered PUFA levels, the fluidity of erythrocyte membranes, which is controlled by the unsaturation degree of phospholipids, may have been reduced in the hypercholesterolaemic situation. The previously observed beneficial effect of dietary capsaicin on the osmotic fragility of erythrocytes of hypercholesterolaemic rats (Kempaiah \& Srinivasan, 2002) may thus be attributable to the partial restoration of the membrane phospholipid and fatty acid profile by capsaicin.

Erythrocyte membranes in hypercholesterolaemic rats in the present study featured significant depletion of PC and an elevated SM concentration, with a consequent higher SM:PC ratio. Dietary capsaicin has partially countered these phospholipid alterations in the erythrocyte membrane of hypercholesterolaemic animals. Significant reduction of the PC concentration and increase of the PS and SM concentrations have been reported in the erythrocytes of atherosclerotic patients (Chien, 1987). The C:P ratio and SM:PC ratio are also significantly increased in atherosclerosis. The increase in SM concentration can be considered as a compensatory change in response to the increase in cholesterol and is aimed at adequately maintaining the physicochemical property (Chien, 1987). SM stabilizes the structure of the bilayer of the cell membrane (Cullis \& Hope, 1980). Diet supplemented with cholesterol has been observed to cause an increase in $18: 1$ and $20: 3$ and decrease in $18: 0$ and $18: 2$ in the erythrocyte PC fraction in rats (Popp-Snijders et al. 1986). An increase in unsaturated fatty acids is compensated by the increase in the C:P ratio in a compensatory mechanism (Brasitus et al. 1985). Considerable increase in fatty acids $18: 1,18: 2$ and $20: 3$ and decrease in the fatty acids 16:0, 18:0 and 20:4 of the PC fraction of the erythrocytes of atherosclerotic patients and, therefore, also an increase in the C:P ratio in erythrocytes associated with a compensatory decrease in 16:0 and 18:0, and an increase in 20:3 and 20:4 in guinea pigs fed an atherogenic diet have been reported (Balachandran \& Ehrhart, 1975).

Lipids compose about $45 \%$ by weight of the RBC membrane, and phospholipids make up about $60 \%$ of the RBC membrane lipid (Lux \& Palek, 1995). The phospholipids are distributed over the outer and inner leaflet of the lipid bilayer in an asymmetric fashion (Verkleij et al. 1973). The choline-containing phospholipids, PC and SM, are localized primarily in the outer monolayer, and the amine-containing phospholipids, PS and PE, are sequestered selectively in the cytofacial monolayer (Bretscher, 1973). The outer monolayer contains all the glycolipids and about $75 \%$ of the membrane PC, while $80 \%$ of the membrane PE is found in the inner layer of the RBC membrane (Person et al. 1996). $\mathrm{PE}$, largely located in the inner leaflet of the membrane, is thought to be renewed by acylation of lysophospholipid, which is apparently a slow process (Popp-Snijders et al. 1986). PC, mainly located in the outer leaflet, is renewed by exchange of PC between the plasma lipoprotein and erythrocyte membrane (Popp-Snijders et al. 1986). Several mechanisms may operate to maintain phospholipid asymmetry: slow flip-flop of endogenous phospholipids; sequestration of inner monolayer lipids by binding to cytofacial proteins; and active transmembrane phospholipid transport. Aminophospholipid-specific transporter or flippase catalyses the ATP-dependent selective translocation of PS and PE from the outer to the inner monolayer (Devaux, 1991). This transporter maintains phospholipid asymmetry, in part by selective inward transport of aminophospholipids.

In the present investigation, the distribution of phospholipids in the outer and inner layer of the membrane of rats was studied by incubating the intact erythrocytes with a combination of phospholipase- $\mathrm{A}_{2}$ (Naja naja venom) and sphingomyelinase (Staphylococcus aureus). An examination of the distribution of various phospholipids in the bilayer of erythrocyte membranes of hypercholesterolaemic rats in the present study has shown decreased concentrations of PC in both the outer and inner monolayer, increased concentration of sphingomyelin in the outer layer, and increased concentration of PE in the inner monolayer. This study has also shown that dietary capsaicin has significantly countered these alterations in the distribution of phospholipids in the erythrocyte membrane bilayer in the hypercholesterolaemic situation.

In erythrocytes, alteration in the proportion of phospholipids between the two leaflets can produce shape changes from discocytes to echinocytes or from discocytes to stromatocytes (Devaux, 1991). Erythrocytes depleted of ATP can become echinocytic and excess ATP leads to stomatocytes (Nakao et al. 1960). These observations can be explained by a redistribution of a small percentage of endogenous phospholipids between the two monolayers, mediated by the ATP-dependent aminophospholipid translocase. The activity of the aminolipid pump modifies the ratio of inner and outer layer lipids and continuous action of the aminolipid pump in the normal physiological state imposes a small excess of phospholipid on the inner layer of the membrane. Verkleij et al. (1973) demonstrated that red cell membrane phospholipid distribution slightly favours the inner monolayer. Only a small percentage of phospholipid net transfer from the inner to the outer monolayer is enough to generate the shape change. During the cholesterol accumulation process, the structure of the membrane is slowly changed. At low 
concentrations, spicules are formed on the membrane and with an increase in cholesterol, erythrocytes acquire an echinocytic appearance leading to decrease in the haematocrit (Vatsala \& Singh, 1980). In bile duct-ligated rats, spur cells (echinocytic) were found in the field of electron microscopy as the cholesterol level increased in the erythrocyte membrane leading to an increase in fragility (Taniguchi et al. 1983).

ESR studies have been made on spin-labelled erythrocyte ghosts using nitroxide derivatives of maleimide compounds. The ratio of signal amplitude of low field transitions for both the weakly (w) bound and the strongly (s) bound spin labels, referred to as the w/s ratio, has been considered to be an extremely sensitive indicator of nitroxide mobility and hence the ratio measures variations in protein conformation and/or environment within the membrane (Barber et al. 1983). ESR studies on erythrocytes with an increased $\mathrm{C}: \mathrm{P}$ ratio in the membrane, from rabbits fed a hypercholesterolaemic diet or human erythrocytes incubated in cholesterol-enriched plasma, revealed a decrease in the w/s ratio, suggesting decreased membrane protein mobility in the hypercholesterolaemic erythrocyte membrane (Kanakaraj et al. 1990). Changes in the ESR spectra of modified membranes are indicators of alteration in the motion and structural organization of membrane components, and have been used to examine a variety of membrane-associated processes (Barber et al. 1985). Studies have shown that alteration in the protein cytoskeleton or membrane lipid composition of erythrocytes can affect membrane fluidity or microviscosity and ultimately the flow properties of erythrocytes (Chabanel et al. 1983). Decreased w/s ratio in the erythrocytes of hypercholesterolaemic rats observed in the present study is suggestive of decreased protein mobility in cholesterol-enriched membranes. Under these conditions, the organization of the proteins in the membrane may be altered, which results in abnormal morphology of the erythrocytes (Kanakaraj et al. 1990). In the present study, where erythrocytes of hypercholesterolaemic rats enriched with cholesterol exhibited a decreased $\mathrm{w} / \mathrm{s}$ ratio in the ESR spectra, both the dietary spice principles effectively reversed this effect probably by their observed ability to decrease membrane cholesterol.

Fluorescence anisotropy of 12-(9-anthroyl) stearic acid was observed to be increased as cholesterol content is increased in erythrocyte membranes resulting in an increased $\mathrm{C}: \mathrm{P}$ ratio when erythrocytes were incubated in varied concentrations of cholesterol liposomes (Vanderkooi \& Chance, 1972). Membrane lipid fluidity is said to be inversely proportional to the fluorescence anisotropy (Hayan et al. 1993). Thus, the increased anisotropy parameter of the erythrocyte membranes in hypercholesterolaemic rats observed in the present study would indicate reduced fluidity. Interestingly, both the dietary spice principles, curcumin and capsaicin, have brought about appreciable reversal in this anisotropy parameter of the erythrocyte membranes in hypercholesterolaemic rats, suggestive of their beneficial influence on the altered erythrocyte fluidity caused by hypercholesterolaemia.

The protein:lipid ratio, C:P ratio, degree of unsaturation of the acyl-chain and the SM content have been implicated as governing factors in maintaining the integrity of biological membranes and influencing their apparent fluidity (Shinitzky \& Barenholz, 1978). In the present study, proteins of erythrocytes of hypercholesterolaemic rats appeared to be unaltered as revealed by SDS-PAGE. But increased cholesterol and altered $\mathrm{C}: \mathrm{P}$ ratio, phospholipid asymmetry and fatty acid composition might have contributed to the altered fluidity, which was evident with a decreased w/s ratio of ESR spectra and increased fluorescence anisotropy.
Erythrocytes of hypercholesterolaemic rats showed a marked decrease in their ability to extrude sodium actively which should lead to impaired regulation of cell volume and then loss of cell deformability and to increased risk of lysis; but there was no lysis of cells. In our study, no significant change in the active efflux of sodium and intracellular sodium concentration was observed in the erythrocytes of hypercholesterolaemic rats. The dietary spice principles, curcumin and capsaicin, contributed to the recovery of membrane fluidity by reversing the altered $\mathrm{C}: \mathrm{P}$ ratio, phospholipid composition and asymmetry, and fatty acid composition of the erythrocyte membrane.

In conclusion, rat erythrocytes appear to be deformed and fragile in the cholesterol-rich plasma of the hypercholesterolaemic animals. This deformity and fragility was partially reversed by dietary curcumin, capsaicin and garlic by virtue of their ability to lower the extent of hypercholesterolaemia. A further insight into the factors that might have reduced the fluidity of erythrocytes in hypercholesterolaemic rats revealed changes in the fatty acid profile of the membranes, phospholipid composition of the membrane bilayer, reduced $\mathrm{Ca}^{2+}, \mathrm{Mg}^{2+}$-ATPase and reduction in the sensitivity of erythrocytes to concanavaline A. Dietary capsaicin appeared partially to counter these changes in hypercholesterolaemic rats. ESR spectra and fluorescence anisotropy parameters also revealed altered fluidity of erythrocytes in hypercholesterolaemic rats. Dietary capsaicin and curcumin significantly reversed this alteration. The higher echinocyte population seen in the erythrocytes of hypercholesterolaemic rats was significantly decreased by dietary capsaicin. Although the spice concentrations employed in this study correspond to roughly five to ten times the level encountered among the Indian population, the effectiveness of lower doses of these spices cannot be ruled out. Consumption of doses of these food additives comparable to the ones used in this study could also be practicable to exploit their beneficial health effect.

\section{References}

Ames BN (1966) Assay of inorganic phosphate, total phosphate and phosphatases. Meth Enzymol 8, 115-118.

Balachandran R \& Ehrhart LA (1975) Metabolic interactions among polyunsaturated fatty acids in response to an atherogenic diet. Proc Soc Exp Biol Med 149, 29-34.

Barber MJ, Rosen GM \& Rauckman EJ (1983) Studies of the mobility of maleimide spin labels within the erythrocyte membrane. Biochim Biophys Acta 732, 126-132.

Barber MJ, Solomonson LP \& Eichler DC (1985) Spin-labeled erythrocyte membrane: direct identification of nitroxide conjugated proteins. Biochem Biophys Res Commun 127, 793-798.

Brasitus TA, Davidson NO \& Schachter D (1985) Variations in dietary triacylglycerol saturation alter the lipid composition and fluidity of rat intestinal plasma membranes. Biochim Biophys Acta 812, 460-472.

Bretscher MS (1973) Membrane structure: some general principles. Science 181, 622-629.

Broekhuyse RM (1968) Phospholipids in tissues of the eye: isolation, characterization and quantitative analysis by two-dimensional thinlayer chromatography of diacyl and vinyl-ether phospholipids. Biochim Biophys Acta 152, 307-315.

Cazana FJD, Puyol MR, Caballero JP, Jimenez AJ \& Duarte AM (1990) Effect of dietary hyperlipidemia-hypercholesterolemia on rat erythrocytes. Int J Vit Nutr Res 60, 393-397.

Chabanel A, Flamm M, Sung KL, et al. (1983) Influence of cholesterol content on red cell membrane viscoelasticity and fluidity. Biophys $J$ 44, 171-176. 
Chien S (1987) Red cell deformability and its relevance to blood flow. Annu Rev Physiol 49, 177-192.

Cooper RA (1977) Abnormalities of cell membrane fluidity in the pathogenesis of disease. N Engl J Med 297, 371-377.

Cullis PR \& Hope MJ (1980) The bilayer stabilizing role of sphingomyelin in the presence of cholesterol: a ${ }^{31}$ P NMR study. Biochim Biophys Acta 597, 533-542.

Devaux PF (1991) Static and dynamic lipid asymmetry in cell membranes. Biochemistry 30, 1163-1173.

Dodgi JT, Mitchell C \& Hanahan DJ (1963) The preparation and chemical characteristics of haemoglobin-free ghosts of human erythrocytes. Arch Biochem Biophys 110, 119-130.

Dowdy S \& Weardew S (1983) Statistics for Research. New York: John Wiley and Sons.

Fairbanks G, Steck TL \& Wallach DFH (1971) Electrophoretic analysis of the major polypeptides of human erythrocyte membrane. Biochemistry 10, 2606-2617.

Hayan I, Cogan U \& Mokaday S (1993) Dietary oxidized oil enhances the activity of $\mathrm{Na}^{+}, \mathrm{K}^{+}$-ATPase and acetylcholinesterase and lowers the fluidity of rat erythrocyte membranes. J Nutr Biochem 4, 563-568.

Kanakaraj P, Meerarani S \& Singh M (1990) Effect of hypercholesterolemia on mobility of erythrocyte membrane proteins. Curr Sci 59, 59-61.

Kempaiah RK \& Srinivasan K (2002) Integrity of erythrocytes of hypercholesterolemic rats during spices treatment. Mol Cell Biochem 236, $155-161$.

Kempaiah RK \& Srinivasan K (2004a) Antioxidant status of red blood cells and liver in hypercholesterolemic rats fed hypolipidemic spices. Int J Vit Nutr Res 74, 199-208.

Kempaiah RK \& Srinivasan K (2004b) Influence of dietary curcumin, capsaicin and garlic on the antioxidant status of red blood cells and the liver in high fat fed rats. Ann Nutr Metab 48, 331-337.

Klenk E \& Langerbeins H (1941) Distribution of neurominic acid in the brain. Z Physiol Chem 270, 185-193.

Levin G, Cogan U, Levy Y \& Mokady S (1990) Riboflavin deficiency and the function and fluidity of rat erythrocyte membranes. J Nutr 120, 857-861.

Liener IE (1955) Haemagglutinin activity of soy in photometric determination. Arch Biochem Biophys 54, 223.

Lux SE \& Palek J (1995) Disorders of the red blood cell membrane. In Blood Principles and Practice of Hematology, pp. 1701-1818 [RI Handin, SE Lux and TP Stassel, editors]. Philadelphia: JB Lippincott Co.

Meenaghan M, Follett GF \& Brophy PJ (1985) Temperature sensitivity of potassium flux into red blood cells in the familial pseudohyperkalaemia. Biochim Biophys Acta 821, 72-78.

Morrison MR \& Smith M (1964) Preparation of fatty acid methyl esters and dimethyl acetals from lipids with boron trifluoride. J Lipid Res $\mathbf{5}$, $600-608$

Nakao M, Nakao T \& Yamozoe S (1960) Adenosine triphosphatase and maintenance of shape of the human red cells. Nature 187, 945-946.
Parker F \& Peterson NF (1965) Quantitative analysis of phospholipids and phospholipid fatty acids from silica gel thin layer chromatograms. $J$ Lipid Res 6, 455-460.

Person SU, Wohlfahrt G, Larsson H \& Gustafson A (1996) Correlation between fatty acid composition of the erythrocyte membrane and blood rheology data. Scand J Clin Lab Invest 56, 183-190.

Popp-Snijders C, Schouten JA, Van Blitterswijk WJ \& Vander Veen EA (1986) Changes in membrane lipid composition of human erythrocytes after dietary supplementation of $n$-3 PUFA: maintenance of membrane fluidity. Biochim Biophys Acta 854, 31-37.

Renooij W, Van Golde LMG, Zwaal RFA \& Van Deenen LM (1976) Topological asymmetry of phospholipid metabolism in rat erythrocyte membranes. Eur J Biochem 61, 53-58.

Rose HG \& Oaklander M (1965) Improved procedure for the extraction of lipids from human erythrocytes. J Lipid Res 6, 428-431.

Ruiz-Gutierrez V, Stiefel P, Villar J, et al. (1993) Cell membrane fatty acid composition in type 1 (insulin-dependent) diabetic patients: relationship with sodium transport abnormalities and metabolic control. Diabetologia 36, 850-856.

Shinitzky M \& Barenholz Y (1978) Fluidity parameters of lipid regions determined by fluorescence polarization. Biochim Biophys Acta 515, 367-394.

Srinivasan K (2000) Spices - valued for more than taste and flavour of foods. In Recent Trends in Spices and Medicinal Plants Research, pp. 31-38 [AK De, editor]. New Delhi: Associated Publishing Co.

Srinivasan K, Sambaiah K \& Chandrasekhara N (2004) Spices as beneficial hypolipidemic food adjuncts: a review. Food Rev Int 20, 187-220.

Steck TL \& Kant JA (1960) Preparation of impermeable ghosts and inside out vesicles from human erythrocyte membranes: acetylcholine esterase accessibility. Meth Enzymol 31, 177.

Taniguchi M, Tanabe F, Ishikawa H \& Sakagami T (1983) Experimental biliary obstruction of rat: initial changes in the structure and lipid content of erythrocytes. Biochim Biophys Acta 753, 22-31.

Vajreswari A, Srinivasa Rao P, Kaplay SS \& Tulpule PG (1983) Erythrocyte membrane in rats fed high erucic acid containing mustard oil: osmotic fragility and lipid composition and $\mathrm{Na}^{+}, \mathrm{K}^{+}-$and $\mathrm{Ca}^{2+}, \mathrm{Mg}^{2+}$-ATPases. Biochem Med 29, 74-84.

Vanderkooi JM \& Chance B (1972) Temperature sensitivity of fluorescence probes in the presence of model membranes and mitochondria. FEBS Lett 22, 23-26.

Vatsala TM \& Singh M (1980) Changes in shape of erythrocytes in rabbits on atherogenic diet and onion extracts. Atherosclerosis 36, 39-45.

Verkleij AJ, Zwaal RFA, Roelofsen B, et al. (1973) The asymmetric distribution of phospholipids in the human red cell membrane: a combined study using phospholipases and freeze-etch electron microscopy. Biochim Biophys Acta 323, 178-193.

Westerman MP, Wiggans RG \& Mao R (1970) Anaemia and hypercholesterolemia in cholesterol fed rabbits. $J$ Lab Clin Med 75, 890-892. 